\title{
Synthesis and photophysical properties of imine borane adducts towards vapochromic materials
}

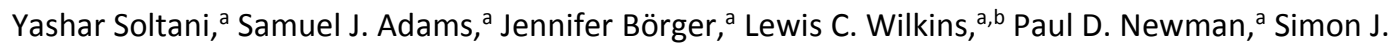
A. Pope*a and Rebecca L. Melen*a

A series of alkynyl aryl conjugated aldehydes and imines were prepared and their adducts with various Lewis acidic boranes have been studied via NMR, absorption, and luminescence spectroscopies in solution. The imine- $B\left(\mathrm{C}_{6} \mathrm{~F}_{5}\right)_{3}$ adduct showed remarkable solution stability, and was then trialled in vapochromism experiments using simple impregnated paper strips to examine the fluorescence responses.

Typically, highly Lewis acidic boranes containing polyfluorinated aryl rings have been used in frustrated Lewis pair (FLP) ${ }^{1,2}$ chemistry to activate substrates for catalysis. Unfortunately, this can sometimes result in drawbacks such as limited functional group tolerance as well as high moisture sensitivity leading to higher catalyst loadings and longer reaction times relative to transition metal-based systems. One major advance in the last few years was the realisation that weakly Lewis basic coordinating solvents could be used in combination with a strong Lewis acid to effect the hydrogenation of ketones. ${ }^{3}$ In addition, the design of moisture-tolerant Lewis acids for FLP chemistry has been targeted ${ }^{4}$ and others, including ourselves, have showed that $\mathrm{B}\left(\mathrm{C}_{6} \mathrm{~F}_{5}\right)_{3}$ can be tolerant to water in metalfree catalytic reactions. ${ }^{5}$ In relation to this, we were interested in gaining a deeper understanding of adduct formation between various Lewis bases in FLP substrates (ketones and imines) and solvents with Lewis acidic boranes. ${ }^{6}$ Such experiments give an insight into the use of Lewis acidic boranes in FLP chemistry and may give an understanding into catalyst activity and inhibition.

The fluorescence properties of Lewis pair adducts have been rarely explored in detail and, in our previous studies into borane catalysed transformations of alkynyl esters, we have frequently encountered strong colouration of the solutions. ${ }^{7}$ Often, reports of luminescence from such systems is confined to the solid-state due to the weakness of the dative interaction upon adduct formation. Previously, $\mathrm{B}\left(\mathrm{C}_{6} \mathrm{~F}_{5}\right)_{3}$ has been shown to alter the optoelectronic properties of conjugated organic chromophores or polymers for potential applications in semiconducting and light harvesting materials. ${ }^{8,9}$ A recent report has also suggested that the luminescence output from Lewis acid-base adducts can be utilised to probe the molecular character of mesoporous organosilicates. ${ }^{10}$ Therefore we were

\footnotetext{
a. School of Chemistry, Cardiff University, Main Building, Park Place, Cardiff CF10

3AT, Cymru/Wales, United Kingdom.

b. Current Address: Department of Chemistry, Texas A\&M University, College

Station, Texas 77843, United States.

c.E-mail: Popesı@cardiff.ac.uk, MelenR@cardiff.ac.uk

Electronic Supplementary Information (ESI) available: Experimental procedures, NMR data, X-ray structures and UV-Vis. measurements.
}

interested to explore the scope of the photophysical properties of a series of Lewis acid-base systems focusing on imine-borane adducts. Secondly, we speculated that these adducts may have applications as potential vapochromic materials with our initial findings showing promise when these adducts are impregnated into paper.

Firstly, a variety of aldehydes 1a-c were synthesised according to literature methods as bases for reaction with boron Lewis acids. ${ }^{9}$ Preliminary ${ }^{11} \mathrm{~B}-\mathrm{NMR}$ studies in $\mathrm{CDCl}_{3}$ of $\mathbf{1 a}$ with a range of boranes of differing Lewis acidity of the type $\mathrm{BR}_{3}$ ( $\mathrm{R}=\mathrm{Ph}, 2,4,6-\mathrm{F}_{3} \mathrm{C}_{6} \mathrm{H}_{2}, \mathrm{C}_{6} \mathrm{~F}_{5}$ ) showed that the tolane derivative 1a only forms adducts with the strongest Lewis acid tris(pentafluorophenyl)borane at room temperature. The more electron rich methoxy-substituted aldehydes $\mathbf{1 b}$ and $\mathbf{1 c}$ form adducts with less Lewis acidic boranes, but not with $\mathrm{BPh}_{3}$ (see supporting information).

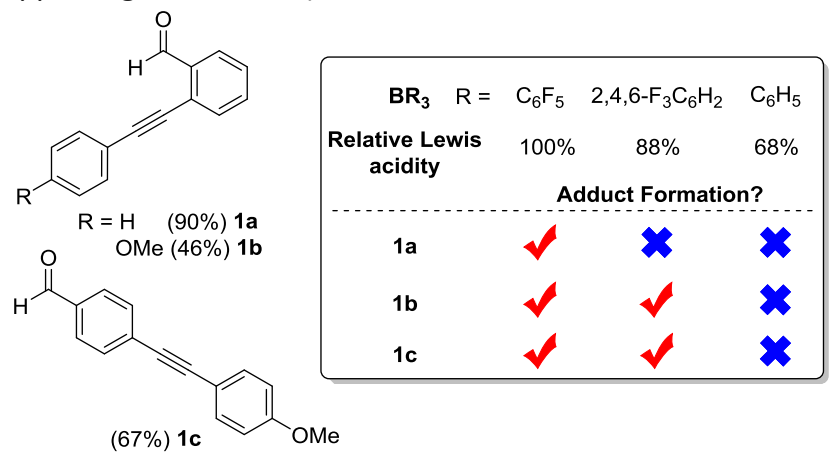

Figure 1. Aldehydes 1a-c and their adduct formation. Relative Lewis acidity determined by the Gutmann-Beckett method. ${ }^{11}$

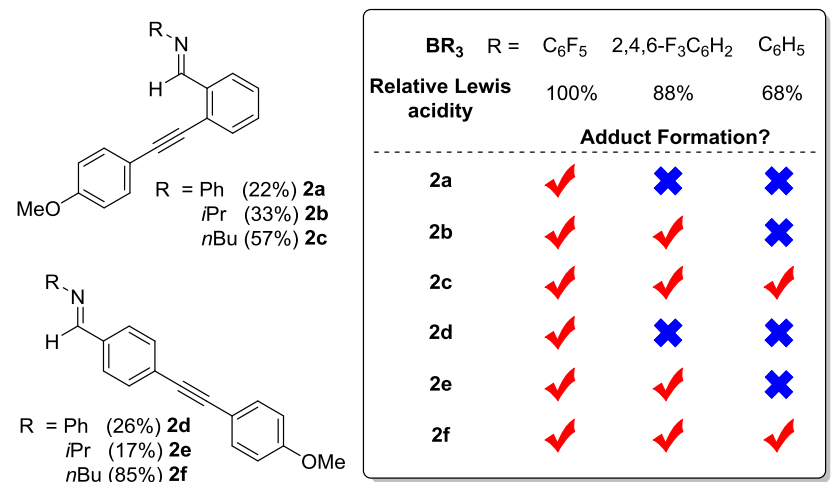

Figure $\mathbf{2}$. Imines $\mathbf{2 a - f}$ and their adduct formation. Relative Lewis acidity determined by the Gutmann-Beckett method. ${ }^{11}$ 
In order to increase the donor ability of the Lewis base, $\mathbf{1 b}$ and 1c were converted into a series of imines by condensation with $\mathrm{PhNH}_{2}, i \mathrm{PrNH}_{2}$ and $n \mathrm{BuNH} \mathrm{H}_{2}$ to yield 2a-f (Figure 2). nButyl substituted imines $\mathbf{2 c}$ and $\mathbf{2 f}$ were anticipated to be the most promising Lewis bases due to their greater positive inductive effect as well as being less sterically demanding than the $i \mathrm{Pr}$ derivatives (2b and $\mathbf{2 e}$ ). Indeed, adduct formation was observed with the less Lewis acidic triphenylborane via ${ }^{11} \mathrm{~B}-\mathrm{NMR}$ spectroscopy (insert, Figure 2). Slow evaporation of a saturated chloroform/hexane solution of $\mathbf{2} f$ and $B\left(C_{6} F_{5}\right)_{3}$ at room temperature under inert atmosphere yielded crystals of the borane adduct which was structurally characterised confirming the proposed formulation (Figure 3 ). The solid-state structure of $\mathbf{2} \mathbf{f} \cdot \mathbf{B}\left(\mathrm{C}_{6} \mathrm{~F}_{5}\right)_{3}$ was as anticipated with the exception of a slight shortening of the $\mathrm{N} \rightarrow \mathrm{B}$ bond when compared with similar motifs $(1.613(3) \AA$ vs. ca. $1.63 \AA$ ) $) .{ }^{11,12}$ This denotes a slightly stronger coordinative interaction between the Lewis acid and base however, this is still significantly longer than related formal $\mathrm{N}-\mathrm{B}$ bonds (ca. $1.39 \AA$ A $)^{12,13}$ Additionally, despite there being the capacity for extensive conjugation throughout the assembly, in the solid-state this delocalisation is broken with the distal aryl ring lying out of the plane of the proximal aryl ring of the imine residue by $41.14(7)^{\circ}$ presumably due to structure packing artefacts.

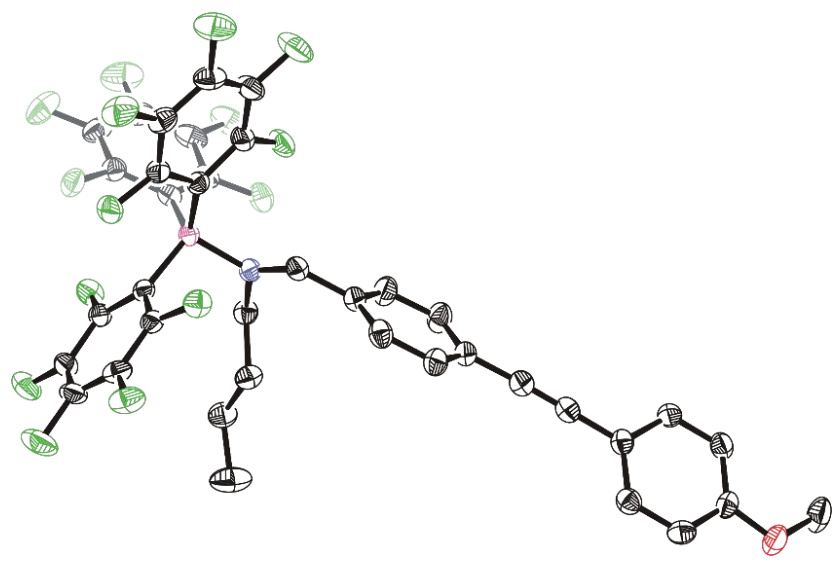

Figure 3. Solid-state crystal structure of $2 \mathbf{f}$ with $B\left(\mathrm{C}_{6} \mathrm{~F}_{5}\right)_{3}$. Thermal ellipsoid set to $50 \%$ probability. $\mathrm{H}$ atoms omitted for clarity. C: black, O: red, $\mathrm{N}$ : blue, B: pink, F: green.

Based on the results above, Lewis acid adducts of imine $\mathbf{2} \mathbf{f}$ were selected for further spectroscopic studies to elucidate their solution-state electronic properties via UV-vis. absorption, and luminescence spectroscopies (Table 1).
Table 1. Photophysical properties of $\mathbf{2} f$ and its adducts in chloroform solution.

\begin{tabular}{|c|c|c|c|}
\hline Compound & $\begin{array}{c}\text { absorption } / \mathrm{nm} \\
\left(\varepsilon / \mathrm{dm}^{3} \mathrm{~mol}^{-1} \mathrm{~cm}^{-1}\right) \\
\end{array}$ & $\begin{array}{c}\text { emission / } \\
\mathrm{nm}^{a}\end{array}$ & $\begin{array}{c}\text { lifetime / } \\
\mathrm{ns}^{b}\end{array}$ \\
\hline $2 f$ & $\begin{array}{c}313(29800), 329 \operatorname{sh}(24200), \\
395 \operatorname{sh}(4000)\end{array}$ & 490 & $\begin{array}{l}1.5(73 \%) \\
6.3(27 \%)\end{array}$ \\
\hline $\mathbf{2 f} \cdot \mathrm{BPh}_{3}$ & $\begin{array}{l}281(46300), 308 \text { sh (22300), } \\
329 \text { sh (17000), } 390(14000)\end{array}$ & 491 & 2.0 \\
\hline $\begin{array}{c}2 \mathrm{ff} \cdot \mathrm{B}(2,4,6- \\
\left.\mathrm{F}_{3} \mathrm{C}_{6} \mathrm{H}_{2}\right)_{3}\end{array}$ & $\begin{array}{c}312(28600), 328 \operatorname{sh}(23000), \\
387 \text { sh }(10000)\end{array}$ & 493 & $\begin{array}{l}1.2(65 \%) \\
3.5(35 \%)\end{array}$ \\
\hline $2 \mathrm{f} \cdot \mathrm{B}\left(\mathrm{C}_{6} \mathrm{~F}_{5}\right)_{3}$ & $\begin{array}{c}312(24500), 330 \mathrm{sh}(13200), \\
397(7400)\end{array}$ & 501 & $\begin{array}{l}1.1(75 \%) \\
3.6(25 \%)\end{array}$ \\
\hline $\begin{array}{c}2 \mathrm{f} \cdot \mathrm{B}(3,4,5- \\
\left.\mathrm{F}_{3} \mathrm{C}_{6} \mathrm{H}_{2}\right)_{3}\end{array}$ & $\begin{array}{l}294 \text { (32800), } 317 \text { sh (19100), } \\
332 \text { sh (16800), } 381 \text { (16800) }\end{array}$ & 490 & 1.7 \\
\hline $\mathbf{2 f} \cdot \mathrm{BF}_{3}$ & $\begin{array}{c}317(21300), 332 \mathrm{sh}(18000), \\
401(14000)\end{array}$ & 496 & 1.3 \\
\hline $\mathbf{2 f} \cdot \mathrm{BCl}_{3}$ & 289 (44300), 399 (23900) & 493 & 1.6 \\
\hline $\mathbf{2 f} \cdot \mathrm{BBr}_{3}$ & 289 (54200), 402 (24000) & 495 & 1.5 \\
\hline
\end{tabular}

${ }^{a}$ using $400 \mathrm{~nm}$ excitation; ${ }^{b}$ using pulsed $295 \mathrm{~nm}$ excitation

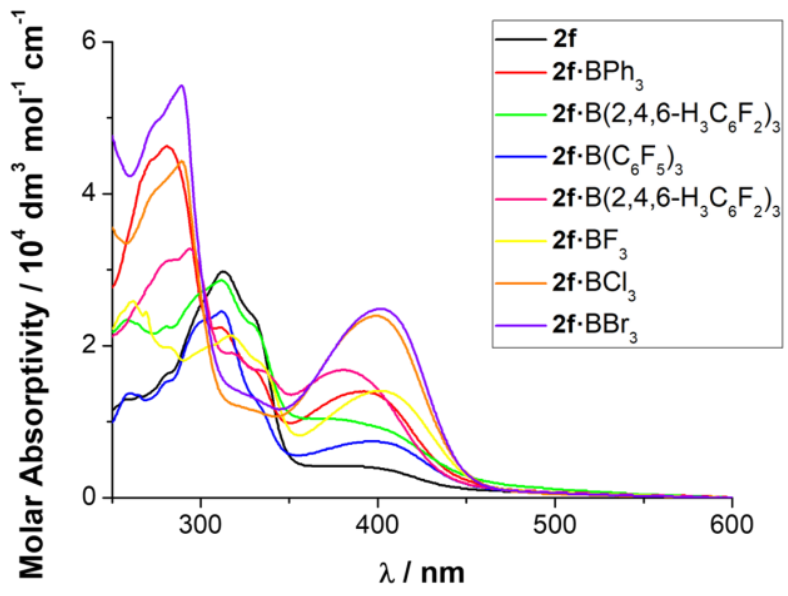

Figure 4. UV-Visible absorption spectra of $\mathbf{2} \mathbf{f}$ and corresponding borane adducts in chloroform solution.

For 2f, the UV-vis. spectrum (Figure 4) revealed three bands at ca. 290, 310 and $390 \mathrm{~nm}$, each of which is likely to have significant $\pi-\pi^{*}$ contributions. This general pattern was replicated for all the borane Lewis acid adducts of $\mathbf{2 f}$, but with a notable increase in intensity of the lowest energy band which was most pronounced for $2 \mathrm{f} \cdot \mathrm{BBr}_{3}\left(\varepsilon \sim 2.5 \times 10^{4} \mathrm{M}^{-1} \mathrm{~cm}^{-1}\right)$. This broad band was also susceptible to subtle wavelength shifts depending upon the nature of the Lewis acid. This renders solutions of these species as different colours to the naked eye, although there was little correlation when comparing these adduct colours to Gutmann-Beckett Lewis acidities. ${ }^{114}$ In comparison, the more sterically hindered ortho-substituted 
imine 2c did not display an absorption band at ca. $400 \mathrm{~nm}$ and its adducts showed only very weak absorption in that region.

Figure 5. Steady state emission spectra of $\mathbf{2 f}$ and adducts in chloroform solution $\left(\lambda_{\mathrm{ex}}=\right.$

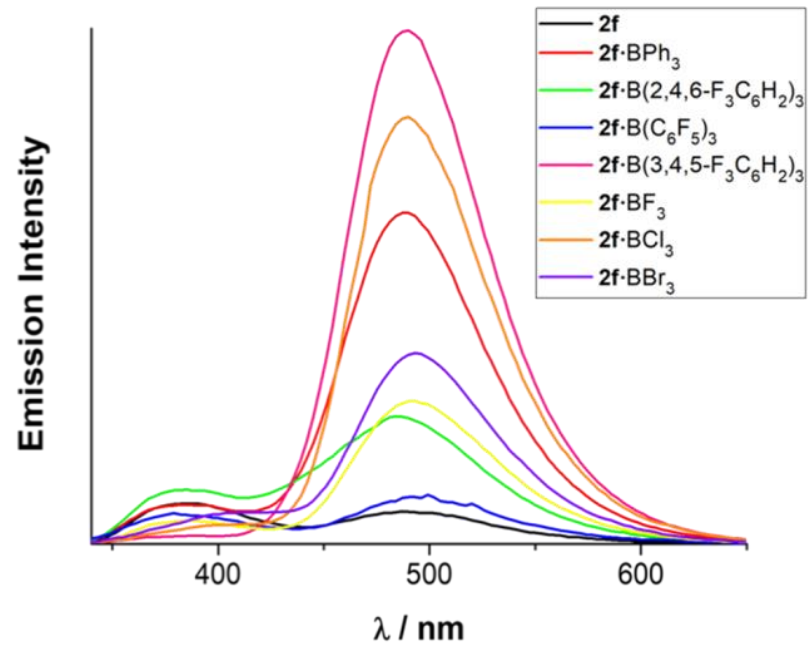

$\left.330 \mathrm{~nm} ; \mathrm{C}=10^{-5} \mathrm{~mol} \mathrm{dm}^{-3}\right)$.

Luminescence studies in chloroform on imine $\mathbf{2} \mathbf{f}$ and its borane adducts were then undertaken using excitation wavelengths of $330 \mathrm{~nm}$ and $400 \mathrm{~nm}$ (the latter data shown in Table 1), thus correlating with the two absorption bands. Excitation at $330 \mathrm{~nm}$ yielded two emission peaks at $c a .380 \mathrm{~nm}$ and $500 \mathrm{~nm}$ (Figure 5), while excitation at $400 \mathrm{~nm}$ selectively reproduced the lower energy emission at $c a .500 \mathrm{~nm}$ (thus resulting in a substantial Stokes' shift). Time-resolved emission analysis of the $500 \mathrm{~nm}$ peak revealed lifetimes of $<10 \mathrm{~ns}$ in each case.

The emission spectra for the Lewis acid derivatives of $\mathbf{2 f}$ (Figure 5) showed that adduct formation results in a dramatic increase in the intensity of the $500 \mathrm{~nm}$ fluorescence band. The precise wavelength of the band was shown to be subtly dependent on the Lewis acid used for adduct formation (e.g. 2f $\cdot B\left(C_{6} F_{5}\right)_{3}$ gave the most bathochromically shifted emission peak) and was also found to be independent of the excitation wavelength ( $330 \mathrm{~nm}$ or $400 \mathrm{~nm}$ ). Solvatochromic luminescence studies on $\mathbf{2 f} \cdot \mathrm{B}\left(\mathrm{C}_{6} \mathrm{~F}_{5}\right)_{3}$ (Figure 6) showed that the band at $c a .500$ $\mathrm{nm}$ was clearly sensitive to solvent polarity, with hexane giving the most hypsochromically shifted peak. The formation of Lewis acid adducts with $\mathbf{2} \mathbf{f}$ thus promotes charge transfer electronic states in these fluorophores, reflecting the donor-acceptor electronic structure of the fluorophore that is induced by Lewis acid-base pair adduct formation. By inference, the lowest energy absorption band at $c a .400 \mathrm{~nm}$ is assigned to a transition with a significant intramolecular charge transfer (ICT) contribution.

The absence of similar observations for $\mathbf{2 c}$ may be due to the reduced conjugation throughout the chromophore caused by the steric demands of this isomer; ortho substitution is clearly unfavourable in this case. Interestingly, the observation of charge transfer bands in $\mathbf{2} f$ at relatively low concentrations (10${ }^{5} \mathrm{M}$ ) is in contrast to the analogous aldehyde 1c (Figure S78, ESI), which does not display any absorption or emission charge transfer bands in chloroform solution, in agreement with previous studies. $^{9}$

Figure 6. Solvatochromic fluorescence spectra of $2 \mathrm{f} \cdot \mathrm{B}\left(\mathrm{C}_{6} \mathrm{~F}_{5}\right)_{3}\left(\lambda_{\mathrm{ex}}=400 \mathrm{~nm}\right)$.
To investigate the stability of the Lewis pair adducts in air, a 10 ${ }^{5} \mathrm{M}$ chloroform solution of $\mathbf{2} \mathrm{f} \cdot \mathrm{B}\left(\mathrm{C}_{6} \mathrm{~F}_{5}\right)_{3}$ was air-equilibrated for

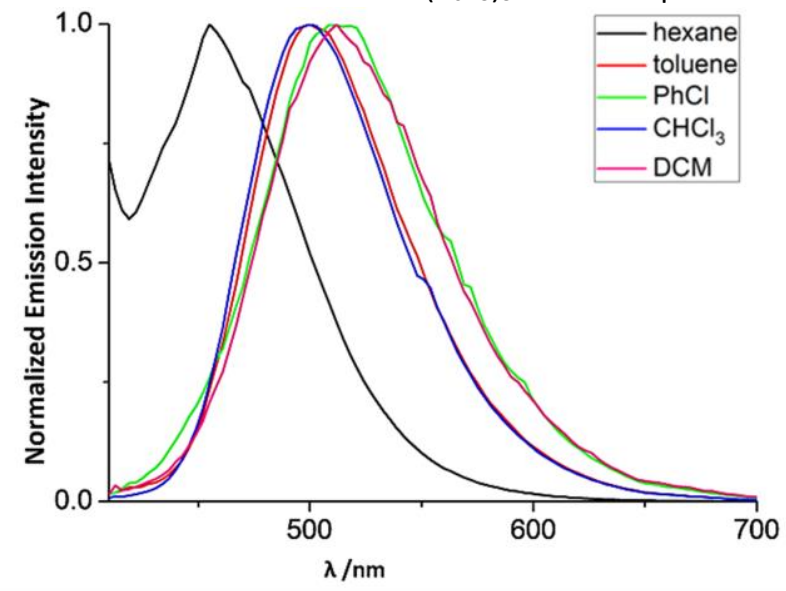

10 minutes. The fluorescence intensity of the charge transfer emission band at $500 \mathrm{~nm}$ was then monitored over 2 hours (Figure S77, ESI) and showed a surprisingly good retention of emission signal intensity over this period.

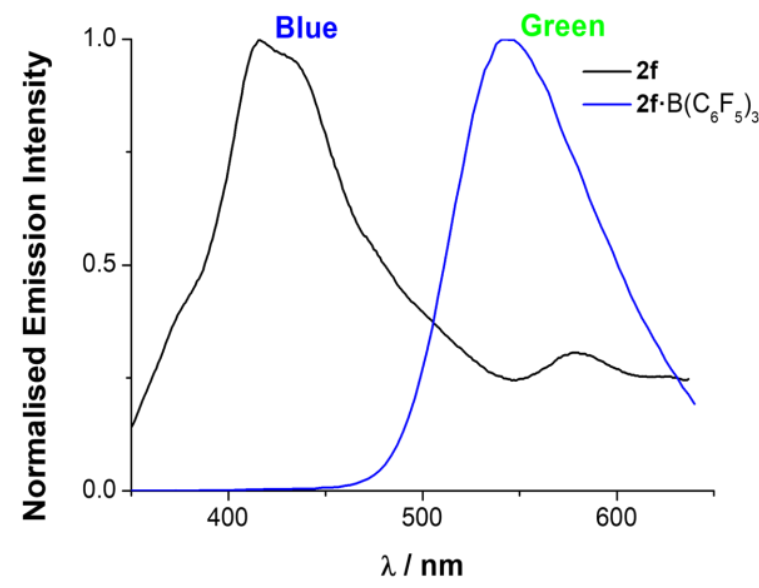

Figure 7. Solid-state film fluorescence spectra of $\mathbf{2 f}$ and $\mathbf{2 f} \cdot B\left(C_{6} F_{5}\right)_{3}\left(\lambda_{\text {ex }}=330 \mathrm{~nm}\right)$.

Further luminescence studies in the solid-state were undertaken on selected species. The solid-state emission spectra for $\mathbf{2} \mathbf{f}$ and $\mathbf{2} \mathbf{f} \cdot \mathbf{B}\left(\mathrm{C}_{6} \mathrm{~F}_{5}\right)_{3}$ revealed emission bands centred at 416 and $541 \mathrm{~nm}$, respectively. Interestingly, these bands are significantly bathochromically shifted from chloroform solution, giving rise to a $40 \mathrm{~nm}$ shift in the case of $\mathbf{2 f} \cdot \mathrm{B}\left(\mathrm{C}_{6} \mathrm{~F}_{5}\right)_{3}$ (Figure 7). It was noted that for $\mathbf{2} f \cdot B\left(C_{6} F_{5}\right)_{3}$ the higher energy emission ascribed to the $\pi-\pi^{*}$ band for the adduct was absent with emission dominated by the proposed ICT band at $541 \mathrm{~nm}$.

The above discussion revealed the apparent photo- and

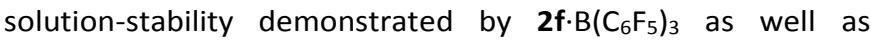
contrasting emission properties in the solid-state. This therefore encouraged us to further explore the application of this species as a potential vapochromic material. Firstly, small strips of filter paper were impregnated with $\mathbf{2} \mathbf{f} \cdot \mathbf{B}\left(\mathrm{C}_{6} \mathrm{~F}_{5}\right)_{3}$ using a concentrated solution of the adduct. Fluorescence from these strips was photographically recorded following excitation at 365 $\mathrm{nm}$ (Figure 8). 


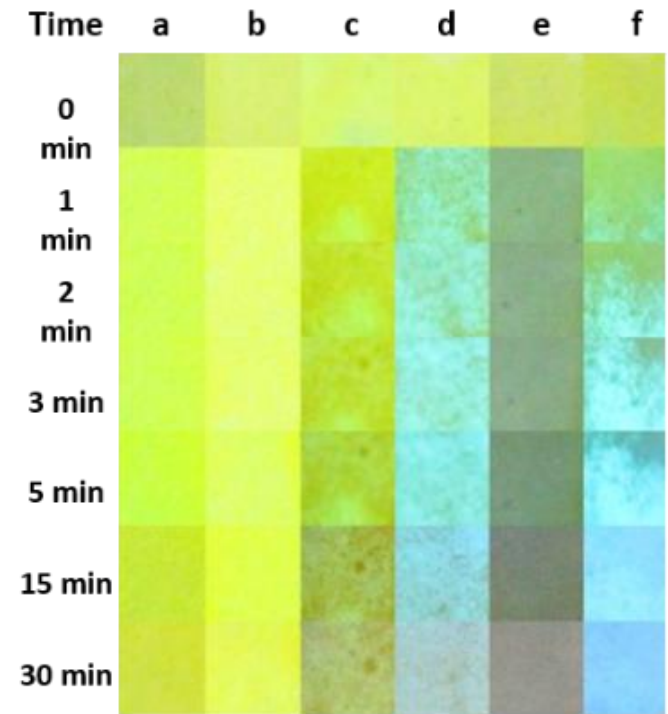

Figure 8. $\mathbf{2 f} \cdot \mathrm{B}\left(\mathrm{C}_{6} \mathrm{~F}_{5}\right)_{3}$ adduct filter strips under UV light $(\lambda=365 \mathrm{~nm})$ exposed to different solvent atmospheres over time (a) blank (b) hexane (c) toluene (d) $\mathrm{Et}_{2} \mathrm{O}$ (e) THF (f) MeOH.

For comparison, $\mathbf{2} \mathbf{f} \cdot \mathbf{B}\left(\mathrm{C}_{6} \mathrm{~F}_{5}\right)_{3}$ was observed in a nitrogen atmosphere, as well as in a vial open to air, and both filter strips showed a similar appearance. Firstly, the visual green fluorescence was still observed after 4 days indicating that solid $\mathbf{2 f} \cdot \mathrm{B}\left(\mathrm{C}_{6} \mathrm{~F}_{5}\right)_{3}$ is relatively bench stable under these conditions. Secondly, the green fluorescence signal correlates well with the solid-state luminescence measurements on $\mathbf{2} \mathbf{f} \cdot \mathbf{B}\left(\mathrm{C}_{6} \mathrm{~F}_{5}\right)_{3}$ (Figure 7). Using a simple set-up (Figure S79, ESI), the impregnated filter strips were then exposed to selected solvent vapours. The visualised fluorescence from the papers strips was recorded at specific time intervals (Figure 8). The coordinating solvents

1 G. C. Welch, R. R. San Juan, J. D. Masuda and D. W. Stephan Science, 2006, 314, 1124.

2 For recent reviews, see a) D. W. Stephan and G. Erker, Angew. Chem. Int. Ed., 2015, 54, 6400; Angew. Chem., 2015, 127 6498; b) D. W. Stephan, Acc. Chem. Res., 2015, 48, 306; c) D. W. Stephan, J. Am. Chem. Soc., 2015, 137, 10018; d)

3 a) T. Mahdi and D. W. Stephan, J. Am. Chem. Soc., 2014, 136, 15809; b) D. J. Scott, M. J. Fuchter and A. E. Ashley, J. Am Chem. Soc., 2014, 136, 15813; c) É. Dorkó, M. Szabó, B. Kótai, I. Pápai, A. Domján and T. Soós, Angew. Chem. Int. Ed., 2017, 56, 9512; Angew. Chem., 2017, 129, 9640; d) M. Bakos, Á. Gyömöre, A. Domján and T. Soós, Angew. Chem. Int. Ed. 2017, 56, 5217; Angew. Chem., 2017, 129, 5301.

4 a) Á. Gyömöre, M. Bakos, T. Földes, I. Pápai, A. Domján and T. Soós, ACS Catal., 2015, 5, 5366.

5 a) V. Fasano, J. E. Radcliffe and M. J. Ingleson, ACS Catal., 2016, 6, 1793; b) L. C. Wilkins, J. L. Howard, S. Burger, L. Frentzel-Beyme, D. L. Browne and R. L. Melen, Adv. Synth. Catal., 2017, 359, 2580; c) V. Fasano and M. J. Ingleson, Chem. -Eur. J., 2017, 23, 2217; d) G. Ghattas, C. Bizzarri, M. Hölscher, J. Langanke, C. Gürtler, W. Leitner and M.-A. Subhani, Chem. Commun., 2017, 53, 3205.

6 D. J. Parks, W. E. Piers, M. Parvez, R. Atencio and M. J. Zaworotko, Organometallics, 1998, 17, 1369.

7 a) L. C. Wilkins, H. B. Hamilton, B. M. Kariuki, A. S. K. Hashmi, M. M. Hansmann and R. L. Melen, Dalton Trans., 2016, 45
$\mathrm{Et}_{2} \mathrm{O}, \mathrm{THF}$ and $\mathrm{MeOH}$ showed a more rapid change in visualised fluorescence output than non-coordinating solvents. After 30 mins the THF sample had already lost green fluorescence, suggesting a disruption in the integrity of the fluorescent $\mathbf{2 f} \cdot \mathrm{B}\left(\mathrm{C}_{6} \mathrm{~F}_{5}\right)_{3}$ adduct. Interestingly, the protic solvent methanol showed a rapid loss in green fluorescence and evolution of a blue emission, allowing easy discrimination from the other solvents. The blue emission is more consistent with the solidstate fluorescence properties of $\mathbf{2} \mathbf{f}$ alone (Figure 7 ). Hexane showed the least effect, as might be expected for a noncoordinating solvent.

In conclusion, we have synthesised a range of Lewis basic imines and studied their adducts with Lewis acidic boranes by various spectroscopic methods. In the case of the nbutyl substituted imine, strong adduct formation was observed with $\mathrm{B}\left(\mathrm{C}_{6} \mathrm{~F}_{5}\right)_{3}$. The stability of this Lewis pair adduct allowed the solution-state electronic properties to be determined showing that ICT electronic transitions give rise to new visible region absorption and fluorescence properties. For a selected example, sufficient air/moisture stability of the adduct facilitated an exploration of its vapochromic properties with a small range of organic solvents. These findings suggest that with further optimisation Lewis pair adducts may be applicable to the design of new vapochromic materials via modulation and discrimination of charge transfer fluorescence properties.

\section{Conflicts of interest}

There are no conflicts to declare.

\section{Notes and references}

5929; b) L. C. Wilkins, B. A. R. Günther, M. Walther, J. R. Lawson, T. Wirth and R. L. Melen, Angew. Chem. Int. Ed., 2016, 55, 11292; Angew. Chem., 2016, 128, 11462; c) Y. Soltani, L. C. Wilkins and R. L. Melen, Angew. Chem. Int. Ed., 2017, 56, 11995; Angew. Chem., 2017, 129, 12157.

8 a) G. C. Welch, R. Coffin, J. Peet and G. C. Bazan, J. Am. Chem. Soc., 2009, 131, 10802; b) G. C. Welch and G. C. Bazan, J. Am. Chem. Soc., 2011, 133, 4632; c) P. Zalar, Z. B. Henson, G. C. Welch, G. C. Bazan and T.-Q. Nguyen, Angew. Chem. Int. Ed., 2012, 51, 7495; Angew. Chem., 2012, 124, 7613; d) D. Tanaka, J. Ohshita, Y. Ooyama and Y. Morihara, Polymer Journal, 2013, 45, 1153; d) J. Huang, Y. Li, Y. Wang, H. Meng, D. Yan, B. Jiang, Z. Wie and C. Zhan, Dyes and Pigments, 2018, 153, 1.

9 M. M. Hansmann, A. Lõpez-Andarias, E. Rettenmeier, C. EglerLucas, F. Rominger, A. S. K. Hashmi and C. Romero-Nieto, Angew. Chem. Int. Ed., 2016, 55, 1196; Angew. Chem., 2016, 128, 1212

10 I. Thiel, A. Fedorov, R. Verel, S. Yakunin, M. V. Kovalenko and C. Coperet, Phys. Chem. Chem. Phys., 2016, 18, 13746.

11 See CSD structures MIVLOS, MIVLUY, MIVMAF, MIVMEJ.

12 F. H. Allen, O. Kennard, D. G. Watson, L. Brammer, A. G. Orpen, R. Taylor, J. Chem. Soc., Perkin Trans. 2, 1987, 0, S1.

13 See CSD structures CUDZUW, CUFBUA, PEFKET.

14 a) U. Mayer, V. Gutmann and W. Gerger, Monatshefte für Chemie, 1975, 106, 1235; b) M. A. Beckett, G. C. Strickland, J. R. Holland and K. S. Varma, Polymer, 1996, 37, 4629. 